\title{
Crowding-Induced Alterations in Vascular System of Wistar- Kyoto Rats: Role of Nitric Oxide
}

\author{
I. BERNÁTOVÁ ${ }^{1}$, A. PÚZSEROVÁ ${ }^{1}$, J. NAVAROVÁ $^{3}$, Z. CSIZMADIOVÁ $^{1,2}$, \\ M. ZEMAN ${ }^{2}$
}

${ }^{1}$ Institute of Normal and Pathological Physiology, Centre of Excellence for Cardiovascular Research, Slovak Academy of Sciences, Bratislava, ${ }^{2}$ Department of Animal Physiology and Ethology, Faculty of Natural Sciences, Comenius University, Bratislava, ${ }^{3}$ Institute of Experimental Pharmacology, Slovak Academy of Sciences, Bratislava, Slovak Republic

Received August 28, 2007

Accepted September 4, 2007

\begin{abstract}
Summary
The aim of this study was to determine the effect of chronic crowding on the cardiovascular system of Wistar-Kyoto (WKY) rats. Rats were randomly divided into the control $\left(480 \mathrm{~cm}^{2}\right.$ per rat) or crowded $\left(200 \mathrm{~cm}^{2}\right.$ per rat) group for eight weeks. Body weight, blood pressure (BP), heart rate and plasma nitrate/nitrite levels of the crowded rats were not different from controls at the end of the experiment. Plasma corticosterone exhibited an increasing trend (5.7 $\pm 1.8 v s$. $12.6 \pm 3.7 \mathrm{ng} / \mathrm{ml}, \mathrm{p}=0.08$ ) while blood glucose was significantly reduced in the crowded rats in comparison with the controls. Nitric oxide (NO) synthase activity and nitrate/nitrite levels of the crowded rats were significantly elevated in the aorta by $\sim 80 \%$ and $\sim 20 \%$, respectively, but unchanged in the left ventricle. Moreover, acetylcholine-induced relaxation was significantly increased in the crowded rats in both the femoral artery $(61 \pm 5 \% v s .76 \pm 5 \%, \mathrm{p}<0.001)$ and mesenteric artery $(51 \pm 6 \%$ vs. $72 \pm 7 \%, \mathrm{p}<0.001)$. In conclusion, results suggest that chronic crowding may increase vasorelaxation and vascular NO production in normotensive rats. This may be considered as an adapting mechanism preventing the development of the stress-related elevation of BP. Additionally, results also suggest caution in the housing of rats because an inappropriate crowding may affect results of the experiment significantly.
\end{abstract}

\section{Key words}

Social stress $\bullet$ Vasorelaxation $\bullet$ Corticosterone $\bullet$ Adaptation

Chronic crowding typically evokes social-stress reactions with prominent psychosocial components mimicking emotional state alterations (Bugajski 1999). Although the crowding is a relatively mild stressor, it affects signal transduction in hypothalamic-pituitaryadrenal responses in rats (Bugajski 1999). In humans, crowded residents had higher levels of urinary catecholamines and greater increases of blood pressure and heart rate during the performance of a challenging task than the uncrowded ones (Fleming et al. 1987), suggesting a deleterious effect of the chronic crowding on cardiovascular regulations. Nevertheless, there are still conflicting data as to the nature of cardiovascular changes induced by stress in normotensive animals (Andrews et 
al. 2003, Grippo et al. 2002). Thus, we have investigated the effect of the chronic crowding on blood pressure, nitric oxide (NO) production and vascular function in normotensive WKY rats.

Twelve-week-old males WKY rats (born in our approved animal facility) were divided into control (480 $\mathrm{cm}^{2} / \mathrm{rat}, 4 \mathrm{rats} /$ cage) and crowded $\left(200 \mathrm{~cm}^{2} / \mathrm{rat}\right.$, 5 rats/cage) groups for eight weeks. Body weight (BW), blood pressure (BP), heart rate (HR), blood glucose, plasma corticosterone and plasma nitrate/nitrite ( $\mathrm{pNit}$ ) levels were determined at the end of the experiment. BP and HR were determined by tail-cuff. Rats were killed by decapitation after a brief $\mathrm{CO}_{2}$ anesthesia between 7.309.30 a.m. Glucose was determined by the Ascensia ENTRUST $^{\circledR}$ blood glucose meter in blood taken from the end of the tail. Plasma corticosterone and pNit were determined from the trunk blood. Plasma corticosterone was determined by RIA (DRG Instruments, Germany) and pNit as well as nitrate/nitrite levels in the aorta and left ventricle were determined by the Griess reaction (Green et al. 1982). NO synthase activity (NOS, determined in homogenates of the aorta and the left ventricle) and the acetylcholine ( $\mathrm{ACh}$ )-induced relaxation of the femoral and first branches of the superior mesenteric artery were measured as described previously (Púzserová et al. 2006). All procedures used in this study were approved by the State Veterinary and Food Administration of the Slovak Republic. Results are presented as mean \pm SEM. BP, HR, BW and vasorelaxation were analyzed using two-way ANOVA and Duncan's test. All other data were analyzed by Student t-test. Values were considered to differ significantly if $\mathrm{p}<0.05$.

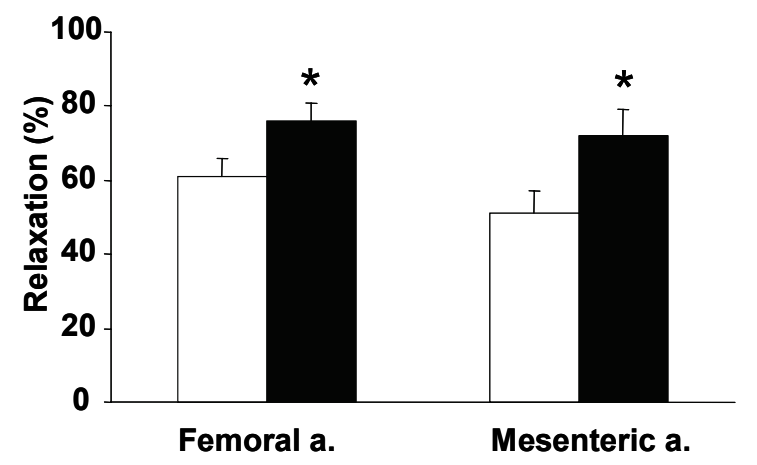

Fig. 1. Acetylcholine-induced relaxation of the femoral and the first branches of the superior mesenteric artery in control (white bar) and crowded (black bar) WKY rats. Values were calculated as the average values of the individual acetylcholine-induced dose-response curves $\left(10^{-5}-10^{-9} \mathrm{~mol} / \mathrm{l}\right)$ in phenylephrineprecontracted vascular rings in isometric conditions. Results are means \pm S.E.M. ${ }^{*} p<0.001$ vs. control.
Table 1. Effect of crowding on selected physiological and metabolic parameters of WKY rats.

\begin{tabular}{lccc}
\hline & n & Control & Crowding \\
\hline $\begin{array}{l}\text { Body weight } \\
\text { (g) }\end{array}$ & 7 & $390 \pm 10$ & $376 \pm 11$ \\
$\begin{array}{l}\text { Blood pressure } \\
\text { (mm Hg) }\end{array}$ & 7 & $110 \pm 3$ & $111 \pm 2$ \\
$\begin{array}{l}\text { Heart rate } \\
\text { (bpm) }\end{array}$ & 7 & $335 \pm 15$ & $344 \pm 10$ \\
$\begin{array}{l}\text { Blood glucose } \\
\text { (mmol/l) }\end{array}$ & 5 & $6.5 \pm 0.2$ & $4.9 \pm 0.2^{*}$ \\
$\begin{array}{l}\text { Plasma corticosterone } \\
\text { (ng/ml) }\end{array}$ & 5 & $5.7 \pm 1.8$ & $12.6 \pm 3.7$ \\
$\begin{array}{l}\text { Plasma nitrite/nitrate } \\
\text { (nmol/ml) }\end{array}$ & 5 & $84 \pm 2$ & $76 \pm 5$ \\
$\begin{array}{l}\text { NOS - Aorta } \\
\text { (pmol/min/mg) }\end{array}$ & 6 & $2.6 \pm 0.2$ & $4.7 \pm 0.5^{*}$ \\
$\begin{array}{l}\text { NOS - LV } \\
\text { (pmol/min/mg) }\end{array}$ & 6 & $2.1 \pm 0.4$ & $2.2 \pm 0.5$ \\
$\begin{array}{l}\text { Nitrate/nitrite - Aorta } \\
\text { (nmol/mg) }\end{array}$ & 5 & $6.7 \pm 0.2$ & $7.9 \pm 0.3^{*}$ \\
$\begin{array}{l}\text { Nitrate/nitrite - LV } \\
\text { (nmol/mg) }\end{array}$ & 5 & $5.4 \pm 0.5$ & $5.8 \pm 0.2$ \\
\hline & & & \\
\hline
\end{tabular}

NOS - nitric oxide synthase activity, LV - left ventricle. Results are means \pm SEM. ${ }^{*} p<0.05$ vs. control.

As described in the Table 1, concentrations of plasma corticosterone in the crowded rats exhibited an increasing trend ( $\mathrm{p}=0.08$ vs. control) and blood glucose was significantly reduced, suggesting a mild stress response. Regarding the cardiovascular response, a given paradigm of the chronic crowding failed to affect BP, HR and plasma nitrate/nitrite of WKY rats. Additionally, no changes were seen in NOS activity and nitrate/nitrite level in the left ventricle. However, in the aorta, NOS activity and nitrate/nitrite level were significantly elevated in the crowded rats. Additionally, the crowding elevated the values of ACh-induced relaxation of both the femoral artery and the mesenteric artery (Fig. 1). This increase was blunted by the NO synthase inhibitor L-NAME (Púzserová et al. 2006). Thus, despite no effect on blood pressure and heart rate, this study has shown that the chronic crowding may affect the glucose metabolism, vascular NO production and vascular function of WKY rats. Similar crowding-induced changes had been previously observed in Wistar rats (Bernátová et al. 2006, 2007). On the other hand, elevated blood 
pressure, reduced NO production and unaltered or reduced vasorelaxation were observed in rats with a positive family history of hypertension, i.e. in borderline and spontaneously hypertensive rats (Bernátová et al. 2007). These observations suggest that elevated NO production in normotensive rats may be considered to be an adapting mechanism preventing the development of the stress-induced elevation of blood pressure. This supports the idea that L-arginine/NO system may act as one of the stress-limiting systems in organism and failure of this system may result in development of a stressrelated hypertension.

In conclusion, results suggest that 8-week crowding supposedly does not represent a significant risk factor for the development of stress-related hypertension in normotensive rats because of their ability to adapt to stressful conditions. However, results also suggest a caution in housing of rats, especially of those involved in cardiovascular studies because inappropriate housing in crowded cages may significantly affect the results of the experiment, regardless the absence of blood pressure changes.

\section{Acknowledgements}

This study was supported by grants Nos. APVT-51008004 and APVT-20-022704, VEGA 2/7064/27 and $2 / 5009 / 25$.

\section{References}

ANDREWS E, JENKINS C, SEACHRIST D, DUNPHY G, ELY D: Social stress increases blood pressure and cardiovascular pathology in a normotensive rat model. Clin Exp Hypertens 25: 85-101, 2003.

BERNÁTOVÁ I, CSIZMADIOVÁ Z, KOPINCOVÁ J, PÚZSEROVÁ A: Effect of chronic stress on vascular responses in rats with borderline and spontaneous hypertension. Physiol Res 55: P15, 2006.

BERNÁTOVÁ I, CSIZMADIOVÁ Z, KOPINCOVÁ J, PÚZSEROVÁ A: Vascular function and nitric oxide production in chronic social-stress-exposed rats with various family history of hypertension. $J$ Physiol Pharmacol 58 (3), 2007, in press.

BUGAJSKI J: Social stress adapts signaling pathways involved in stimulation of the hypothalamic-pituitary-adrenal axis. J Physiol Pharmacol 50: 367-379, 1999.

FLEMING I, BAUM A, DAVIDSON LM, RECTANUS E, MCARDLE S: Chronic stress as a factor in physiologic reactivity to challenge. Health Psychol 6: 221-237, 1987.

GREEN LC, WAGNER DA, GLOGOWSKI J, SKIPPER PL, WISHNOK JS, TANNENBAUM SR: Analysis of nitrate, nitrite, and $\left[{ }^{15} \mathrm{~N}\right]$ nitrate in biological fluids. Anal Biochem 126: 131-138, 1982.

GRIPPO AJ, MOFFITT JA, JOHNSON AK: Cardiovascular alterations and autonomic imbalance in an experimental model of depression. Am J Physiol 282: R1333-R1341, 2002.

PÚZSEROVÁ A, CSIZMADIOVÁ Z, ANDRIANTSITOHAINA R, BERNÁTOVÁ I: Vascular effects of red wine polyphenols in chronic stress-exposed Wistar-Kyoto rats. Physiol Res 55 (Suppl 1): S39-S47, 2006.

\section{Corresponding author}

I. Bernátová, Institute of Normal and Pathological Physiology, Slovak Academy of Sciences, Sienkiewiczova 1,81371

Bratislava, Slovak Republic. E-mail: Iveta.Bernatova@savba.sk 